\title{
The ICF Classification System to Assess Risk Factors for CVD in Secondary Prevention after Ischemic Stroke and Intracerebral Hemorrhage
}

\author{
Mateusz Lucki ${ }^{1, *(\mathbb{D}}$, Ewa Chlebuś ${ }^{2} \mathbb{D}$, Agnieszka Wareńczak $^{2} \mathbb{D}$ and Przemysław Lisiński ${ }^{2}$ (D) \\ 1 Department of Cardiology, Hospital Center of the Jelenia Góra Valley, 58-506 Jelenia Góra, Poland \\ 2 Department of Rehabilitation and Physiotherapy, University of Medical Sciences, 60-545 Poznań, Poland; \\ ewachlebus@ump.edu.pl (E.C.); agnieszka.warenczak@gmail.com (A.W.); plisinski@vp.pl (P.L.) \\ * Correspondence: mat539@interia.pl; Tel.: +48-506-474-083
}

Citation: Lucki, M.; Chlebuś, E.; Wareńczak, A.; Lisiński, P. The ICF Classification System to Assess Risk Factors for CVD in Secondary Prevention after Ischemic Stroke and Intracerebral Hemorrhage. Medicina 2021, 57, 190. https://doi.org/ 10.3390/medicina57030190

Academic Editor: Sun Im

Received: 14 January 2021

Accepted: 19 February 2021

Published: 24 February 2021

Publisher's Note: MDPI stays neutral with regard to jurisdictional claims in published maps and institutional affiliations.

Copyright: (c) 2021 by the authors. Licensee MDPI, Basel, Switzerland. This article is an open access article distributed under the terms and conditions of the Creative Commons Attribution (CC BY) license (https:// creativecommons.org/licenses/by/ $4.0 /)$.

\begin{abstract}
Background and objectives: Patients with a history of prior stroke have a high risk for subsequent cardiovascular events (CVD). Therefore, the implementation of an effective strategy to reduce risk factors and thereby improve secondary prevention outcomes is crucial in this patient population. The aim of this study was to determine differences in the incidence of risk factors for recurrent CVD events based on clinical type of prior stroke and to characterize them using the ICF (International Classification of Functioning, Disability and Health) classification system. Materials and Methods: The incidence of risk factors for recurrent CVD events were retrospectively analyzed in 109 patients with a history of ischemic stroke (IS) and 80 patients with a history of intracerebral hemorrhage (ICH) within 14 days poststroke. Results: Atrial fibrillation/flutter $(p=0.031),>70 \%$ carotid artery stenosis $(p=0.004)$, blood pressure $>140 / 90 \mathrm{mmHg}(p=0.025)$, blood HbA1c levels $>7 \%(p=0.002)$, smoking $(p=0.026)$ and NSAID (nonsteroidal anti-inflammatory drug) use $(p<0.001)$ were significantly more common in patients with a history of ischemic stroke. However, liver function test abnormalities were observed more commonly in patients with a history of hemorrhagic stroke $(p=0.025)$. Conclusions: The incidence and type of risk factors for recurrent CVD events vary according to the clinical type of prior stroke. The ICF classification system is a useful tool for evaluating these risk factors. This may help reduce the risk of subsequent CVD events.
\end{abstract}

Keywords: stroke; CVD risk factors; secondary prevention; ICF

\section{Introduction}

Patients with a history of prior stroke have a high risk for subsequent cardiovascular events (CVD) [1]. The risk of recurrence is $1.7-4 \%$ in the 30 days after the first episode, $6-12 \%$ in the first year, and $19-42 \%$ in the next 5 years after the first stroke. The prognostic factors for a recurrent stroke depend on the time after the first stroke. There are risk factors for early recurrence (up to 30 days) and late recurrence (30 days after the initial stroke) [2]. However, about $80 \%$ of recurrent cardiovascular events could be prevented if major risk factors are eliminated [3]. Close monitoring of the modifiable risk factors for CVD is crucial for the prevention of recurrent CVD events in the primary health care and ambulatory specialist care settings [4]. The widely recognized modifiable risk factors in secondary prevention of CVD include comorbid conditions (arterial hypertension, atrial fibrillation/flutter, carotid artery disease, depression, insomnia, diabetes mellitus, dyslipidemia, abnormal value of BMI (Body Mass Index)), renal and liver impairment, medication use and certain lifestyle characteristics (smoking, alcohol abuse) [5-20]. It is worthy of note that coincidence of these risk factors is associated with increased rates of recurrent cardiovascular events [21]. Therefore, it is advisable to monitor all of these factors at the same time. The International Classification of Functioning, Disability, and Health (ICF) helps to systematize various clinical data from medical records and present 
them in a clear graphical form that can be used for comparison and differentiation [22]. The ICF classification makes it possible to combine neurological deficits with activity disturbance in certain activities of everyday life. Moreover, it facilitates the verification and evaluation of the functional state evaluation. Knowledge of the functional abilities of patients, documented in commonly used clinical tests after recoding on the ICF scale, increases the reliability of a comprehensive patient assessment [23]. In practical terms, the ICF classification has so far been used in poststroke patients at the stage of early diagnosis and in the acute stage of stroke treatment [24]. It is of note that, according to the available literature, ICF classification has never been used in secondary prevention to assess CVD risk factors in patients with prior stroke.

\section{Objective}

1. To identify differences in the incidence of risk factors for recurrent CVD events based on clinical type of prior stroke.

2. To use the ICF category charts as a tool for determining differences in the incidence of risk factors for recurrent CVD events in patients with a history of prior ischemic stroke (IS) and intracerebral hemorrhage (ICH).

\section{Materials and Methods}

\subsection{Study Population/Inclusion and Exclusion Criteria}

The study had retrospective design and involved the analysis of risk factors for recurrent CVD events based on data from medical records of patients who were admitted to the Department of Neurological Rehabilitation in the Wiktor Dega Memorial Orthopedic \& Rehabilitation Teaching Hospital in Poznań within 14 days of stroke between December 2017 and September 2020. The patients were divided into 2 groups based on prior history of ischemic or hemorrhagic stroke. The study was approved by the Ethics Committee at the Karol Marcinkowski Memorial Medical University in Poznań (Approval No. 810/2017 of 22 June 2017). The study was conducted in accordance with ethical principles for biomedical research as stated in the Declaration of Helsinki. The study was registered in the Clinical Trial Registry: NCT04590287 https:/ / clinicaltrials.gov/ct2/show / NCT04590287 (accessed on 19 October 2020).

Inclusion criteria: (1) history of a new-onset ischemic or hemorrhagic stroke; (2) stroke documented by imaging studies; (3) early hospitalization for stroke ( $\leq 14$ days after diagnosis) at the department of neurological rehabilitation; (4) complete medical records in respect to the risk factors of interest.

Exclusion criteria: (1) history of multiple strokes; (2) no imaging studies available to confirm the history of stroke; (3) late hospitalization for stroke ( $>14$ days after diagnosis) at the department of neurological rehabilitation; (4) the lack of complete medical records in respect to the risk factors of interest.

\subsection{Statistical Analysis}

The data were analyzed using Statistica version 13.1 software. Descriptive statistics were reported as means, standard deviation (SD), median, minimum, and maximum. Categorical variables were expressed as counts and frequencies. The Shapiro-Wilk test was used to assess the normality of distributions in the test score. Due to non-normally distributed data, the nonparametric U Mann-Whitney test was used to compare outcomes between the IS and HS groups. The chi-squared test was employed to compare differences between groups for categorical variables. $p$-values of less than 0.05 were considered statistically significant. A post hoc evaluation of the power of the study showed following values: hypertension a power of 0.57 , coronary heart disease a power of 0.87 , chronic heart failure a power of 0.73 , type 2 diabetes mellitus (DM) a power of 0.87 , carotid artery disease a power of 0.99 , epilepsy a power of 0.73 . 


\subsection{ICF Profile}

The analysis involved the prevalence of risk factors for recurrent CVD events among patients with a prior history of ischemic stroke or hemorrhagic stroke as described in the literature. Specific codes and their respective qualifiers were assigned to each ICF category according to the ICF classification:

The effect of depressive disorders on the risk of a recurrent CVD event was assessed using ICF category b152: emotional functions. The following Beck Depression Inventory (BDI) scores were used to measure the severity of depression [25]: qualifier 0: BDI total score 0 to 11 -no depression; qualifier 2: BDI total score 12 to 19 -mild depression; qualifier 3: BDI total score 20 to 25-moderate depression; qualifier 4: BDI total score 26 to 63 -severe depression.

The effect of sleep disturbance on the risk of a recurrent CVD event was assessed using ICF category b134: sleep functions. The following criteria were used to measure the severity of insomnia [6]: qualifier 0-no sleep disturbance (sleep time 6-9 h); qualifier 4 - sleep disturbance (sleep time $<6$ or $>9 \mathrm{~h}$ ).

The increased risk of CVD related to heart rate (HR) was estimated using ICF category b4100: heart rate. The following criteria were used to quantify heart rate disorders [7]: qualifier $0-\mathrm{HR}<80 / \mathrm{min}$; qualifier $4-\mathrm{HR}>80 / \mathrm{min}$. Heart rhythm disorders were encoded as ICF category b4101: heart rhythm. The following criteria were used [8]: qualifier 0-normal sinus rhythm; qualifier 4-atrial fibrillation.

The effect of carotid artery stenosis on the risk of a recurrent CVD event was assessed using ICF category b4150: functions of arteries. The following criteria were used [9]: qualifier $0-<50 \%$ carotid stenosis; qualifier $3-50 \%$ to $69 \%$ carotid stenosis; qualifier $4 \longrightarrow 70 \%$ carotid stenosis.

The effect of increased blood pressure (BP) on the risk of a recurrent CVD event was assessed using ICF category b4200: increased blood pressure. The following BP values were used [26]: qualifier $0-\mathrm{BP}<130 / 80 \mathrm{~mm} / \mathrm{Hg}$; qualifier $1-\mathrm{BP}>130 / 80 \mathrm{~mm} / \mathrm{Hg}$; qualifier 2-BP > 140/90 mm/Hg; qualifier 3-BP > 160/90 mm/Hg; qualifier 4-BP > $180 / 110 \mathrm{~mm} / \mathrm{Hg}$.

The effect of liver and renal impairment on the risk of a recurrent CVD event was assessed using ICF category b4301: metabolite-carrying functions of the blood. The following criteria were used to classify renal impairment [27]: qualifier 0-estimated glomerular filtration (eGFR) $>90 \mathrm{~mL} / \mathrm{min} / 1.73 \mathrm{~m}^{2}$; qualifier 1 -eGFR $60-89 \mathrm{~mL} / \mathrm{min} / 1.73 \mathrm{~m}^{2}$; qualifier 2-eGFR 30-59 mL/min $/ 1.73 \mathrm{~m}^{2}$; qualifier 3-eGFR $15-29 \mathrm{~mL} / \mathrm{min} / 1.73 \mathrm{~m}^{2}$; qualifier 4-eGFR $<15 \mathrm{~mL} / \mathrm{min} / 1.73 \mathrm{~m}^{2}$, and liver impairment [12]: qualifier 0 -bilirubin level $<2 \times$ the upper limit of normal (ULN) and ALT(alanine transaminase)/AST(aspartate transaminaze) / ALP(alkaline phosphatase) $<3 \times$ ULN; qualifier 4-bilirubin level $>2 \times \mathrm{ULN}$ and ALT / AST / ALP $>3 \times$ ULN.

Patients receiving anticoagulants have an increased risk of bleeding [13]. This parameter was encoded as ICF category b4302: functions related to the coagulation of blood. If taking VKA (vitamin K antagonist) following values were used: qualifier 0-NO; qualifier 4-YES. If taking NOAC (non-vitamin $\mathrm{K}$ antagonist) following values were used: qualifier 0-NO; qualifier 4-YES.

The effect of impaired glycemic control on the risk of recurrent CVD event was assessed using ICF category b5401, carbohydrate metabolism. The following HbA1c (glycated hemoglobin 1c) values were used [28]: qualifier $0-\mathrm{HbA1c}<7 \%$; qualifier $4-\mathrm{HbA} 1 \mathrm{c}>7 \%$.

The effect of LDL-C (low-density lipoprotein cholesterol) levels on the risk of a recurrent CVD event was assessed using ICF category b7302, lipid metabolism. The following LDL-C values were used [29]: qualifier $0-\mathrm{LDL}-\mathrm{C}<55 \mathrm{mg} / \mathrm{dL}$; qualifier $2-\mathrm{LDL}-\mathrm{C}$ 55-70 mg/dL, qualifier 3-LDL-C $71 \mathrm{mg} / \mathrm{dL}-115 \mathrm{mg} / \mathrm{dL}$, qualifier 4-LDL-C > $116 \mathrm{mg} / \mathrm{dL}$.

Alcohol consumption is an additional risk factor associated with increased risk of a recurrent CVD event. This risk factor was assessed using ICF category e1100, food: alcohol consumption. The following criteria were used [30]: qualifier 0-alcohol intake per day $<10 \mathrm{~g}$; qualifier 4-alcohol intake per day $>10 \mathrm{~g}$. 
The increased risk of CVD related to NSAIDs (nonsteroidal anti-inflammatory drugs) [17] and to smoking [18] was estimated using ICF categories e1101, drugs and e1109, products or substances for personal consumption, respectively. The following criteria were used: qualifier 0-NO; qualifier 4-YES.

Then, a percentage distribution of ICF category qualifiers was graphically represented using color coding in order to highlight differences in the type and incidence of individual risk factors for recurrent CVD events between clinical types of stroke: qualifier 0-no risk factor is present if the percentage distribution ranges from $0 \%$ to $4 \%$, color code: dark green; qualifier 1-low prevalence of the risk factor if the percentage distribution ranges from $5 \%$ to $24 \%$, color code: light green; qualifier 2-moderate prevalence of the risk factor if the percentage distribution ranges from $25 \%$ to $49 \%$, color code: yellow; qualifier 3-high prevalence of the risk factor if the percentage distribution ranges from $50 \%$ to $95 \%$, color code: orange; qualifier 4-extremely high prevalence of the risk factor if the percentage distribution ranges from $96 \%$ to $100 \%$, color code: red.

\section{Results}

\subsection{Study Population Characteristics}

The study groups comprised 109 patients with a history of prior ischemic stroke (IS) and 80 patients with a history of prior intracerebral hemorrhage (ICH). There was a significant difference between study groups with respect to patients' age $(p<0.001)$. The median age was 69.3 years in IS group (SD \pm 14.8 ), and 59.4 years in ICH group (SD \pm 14.0 ). There were more women (50.50\%) among IS patients, and more men (57.50\%) among ICH patients. Furthermore, the incidence of comorbid conditions such as hypertension $(p=0.025)$, coronary heart disease $(p=0.001)$, chronic heart failure $(p=0.013)$, type 2 diabetes mellitus $(p=0.002)$ and carotid artery disease $(p=0.013)$ was significantly higher in the IS group. However, the incidence of comorbid epilepsy was significantly higher in the ICH group $(p=0.009)$. The detailed characteristics of the study population are provided in Table 1.

Table 1. Study population characteristics.

\begin{tabular}{|c|c|c|c|c|}
\hline & & Ischemic Stroke & $\begin{array}{l}\text { Intracerebral } \\
\text { Hemorrhage }\end{array}$ & $p$-Value \\
\hline Sex & $\begin{array}{l}\mathrm{F} n(\%) \\
\mathrm{M} n(\%)\end{array}$ & $\begin{array}{l}55(50.50 \%) \\
54(49.50 \%)\end{array}$ & $\begin{array}{l}34(42.50 \%) \\
46(57.50 \%)\end{array}$ & 0.279 \\
\hline Age & $\begin{array}{l}\text { Mean } \pm \text { SD (years) } \\
\text { Median (years) } \\
\text { Minmax (years) }\end{array}$ & $\begin{array}{c}69.3 \pm 14.8 \\
71 \\
51-93\end{array}$ & $\begin{array}{c}59.4 \pm 14.0 \\
61 \\
49-84\end{array}$ & $<0.001$ * \\
\hline Treatment of stroke & $\begin{array}{c}\text { Medical } \\
\text { (pharmacological) } n(\%) \\
\text { Interventional } n(\%)\end{array}$ & $\begin{array}{l}87(79.80 \%) \\
22(20.20 \%)\end{array}$ & $\begin{array}{l}60(75.00 \%) \\
20(25.00 \%)\end{array}$ & 0.431 \\
\hline \multicolumn{5}{|c|}{ Comorbidities } \\
\hline $\begin{array}{c}\text { Hypertension } \\
\text { Coronary heart disease } \\
\text { Chronic heart failure } \\
\text { Type } 2 \text { DM } \\
\text { Carotid artery disease } \\
\text { Epilepsy }\end{array}$ & $\begin{array}{l}n(\%) \\
n(\%) \\
n(\%) \\
n(\%) \\
n(\%) \\
n(\%)\end{array}$ & $\begin{array}{c}104(95.4 \%) \\
26(23.90 \%) \\
8(7.30 \%) \\
36(33.00 \%) \\
32(29.63 \%) \\
8(7.30 \%)\end{array}$ & $\begin{array}{c}69(86.30 \%) \\
6(7.50 \%) \\
0(0.00 \%) \\
11(13.80 \%) \\
4(5.00 \%) \\
16(20.00 \%)\end{array}$ & $\begin{array}{l}0.025 \\
0.001 \\
0.013 \\
0.002 \\
0.013 \\
0.009\end{array}$ \\
\hline
\end{tabular}

Chi-squared test, * Mann-Whitney test, Type 2 DM—type 2 diabetes mellitus, F-females, M-males, $n$-size of the sample, SD—standard deviation, ICH-intracerebral hemorrhage, IS-ischemic stroke.

\subsection{The Incidence of Risk Factors for Recurrent CVD Events}

The incidence of risk factors for recurrent CVD events according to the clinical type of prior stroke is provided in Table 2. The incidence of atrial fibrillation/flutter $(p=0.031)$, $>70 \%$ carotid artery stenosis $(p=0.004)$, increased blood pressure $(p=0.025)$, increased blood HbA1c $(p=0.002)$, smoking $(p=0.026)$ and NSAID use $(p<0.001)$ was significantly higher 
in IS patients compared to the ICH group. The incidence of liver function test abnormalities was significantly higher in ICH patients compared to the IS group $(p=0.025)$. There were no significant differences between IS and ICH groups in the incidence of depression, insomnia, heart rate, $50 \%$ to $69 \%$ carotid stenosis, renal impairment $\left(e G F R<15 \mathrm{~mL} / \mathrm{min} / 1.73 \mathrm{~m}^{2}\right.$ ), VKA/NOAC use, lipid metabolism and alcohol consumption.

Table 2. The incidence of cardiovascular disease (CVD) risk factors in secondary prevention according to the clinical type of prior stroke.

\begin{tabular}{|c|c|c|c|c|}
\hline & & Ischemic Stroke & $\begin{array}{l}\text { Intracerebral } \\
\text { Hemorrhage }\end{array}$ & $p$-Value \\
\hline b 152 Emotional functions-Depression [5] & $n(\%)$ & $26(23.90 \%)$ & $20(25 \%)$ & 0.886 \\
\hline b 134 Sleep functions-Insomnia [6] & $n(\%)$ & $28(25.70 \%)$ & $30(37.50 \%)$ & 0.082 \\
\hline b 4100 Heart rate [7] & $\mathrm{HR}>80 / \mathrm{min}, n(\%)$ & $49(47.10 \%)$ & $32(40.00 \%)$ & 0.355 \\
\hline b 4101 Heart rhythm [8] & $\begin{array}{c}\text { Atrial fibrillation/flutter, } n \\
\qquad(\%)\end{array}$ & $32(29.62 \%)$ & $13(16.25)$ & 0.031 \\
\hline \multirow{2}{*}{ b 4150 Functions of arteries [9] } & Stenosis $50-69 \%, n(\%)$ & $8(8.00 \%)$ & $3(7.90 \%)$ & 0.984 \\
\hline & Stenosis $>70 \%, n(\%)$ & $24(24.00 \%)$ & $1(2.60 \%)$ & 0.004 \\
\hline b 4200 Increased blood pressure [10] & $>140 / 90 \mathrm{mmHg}, n(\%)$ & $104(95.40 \%)$ & $69(86.30 \%)$ & 0.025 \\
\hline \multirow{2}{*}{$\begin{array}{l}\text { b } 4302 \text { Metabolite-carrying functions of the } \\
\text { blood }[11,12]\end{array}$} & $\begin{array}{c}\mathrm{eGFR}<15 \mathrm{~mL} / \mathrm{min} / 1.73 \mathrm{~m}^{2}, \\
n(\%)\end{array}$ & $30(27.52 \%)$ & $10(12.5 \%)$ & 0.079 \\
\hline & $\begin{array}{c}\text { Bilirubin }>2 \times \text { ULN, } \\
\text { ALT } / \text { AST } / \text { ALP }>3 \times \text { ULN, } n \\
(\%)\end{array}$ & $5(4.60 \%)$ & $11(13.80 \%)$ & 0.025 \\
\hline \multirow{2}{*}{$\begin{array}{l}\text { b } 4303 \text { Clotting functions. Functions related } \\
\text { to the coagulation of blood [13] }\end{array}$} & VKA, $n(\%)$ & $22(20.18 \%)$ & $11(13.75 \%)$ & 0.250 \\
\hline & NOAC, $n(\%)$ & $12(11.01 \%)$ & $3(3.75 \%)$ & 0.068 \\
\hline b 5401 Carbohydrate metabolism [14] & $\mathrm{HbA} 1 \mathrm{c}>7 \%, n(\%)$ & $36(33.00 \%)$ & $11(13.80 \%)$ & 0.002 \\
\hline \multirow{3}{*}{ b 7302 Lipid metabolism [15] } & LDL 70-55 mg/dL, $n(\%)$ & $5(6.25 \%)$ & $1(3.03 \%)$ & 0.488 \\
\hline & LDL $115-71 \mathrm{mg} / \mathrm{dL}, n(\%)$ & $31(38.75 \%)$ & $16(48.48 \%)$ & 0.34 \\
\hline & $\mathrm{LDL}>116 \mathrm{mg} / \mathrm{dL}, n(\%)$ & $41(51.25 \%)$ & $16(48.48 \%)$ & 0.789 \\
\hline e1100 Food [16] & $\begin{array}{l}\text { Alcohol consumption }>10 \mathrm{~g} \\
\qquad(>1 \text { unit }), n(\%)\end{array}$ & $5(4.60 \%)$ & $5(6.30 \%)$ & 0.614 \\
\hline e 1101 Drugs [17] & NSAIDs, $n(\%)$ & $88(80.70 \%)$ & $11(13.80 \%)$ & 0.001 \\
\hline $\begin{array}{l}\text { e1109 Products or substances for personal } \\
\text { consumption, other specified [18] }\end{array}$ & Smoking, $n(\%)$ & $33(30.30 \%)$ & $13(16.30 \%)$ & 0.026 \\
\hline
\end{tabular}

Chi-squared test ALT—Alanine aminotransferase; AST—Aspartate aminotransferase; ALP—Alkaline phosphatase; CVD—Cardiovascular disease; eGFR -Estimated glomerular filtration rate; HbA1c-Glycated hemoglobin 1c; HR-Heart rate; LDL-C—Low-density lipoprotein cholesterol; NOAC - Non-vitamin K antagonist oral anticoagulants; NSAIDs-Nonsteroidal anti-inflammatory drugs; ULN-Upper limit of normal, VKA-Vitamin K antagonist.

\subsection{CVD Risk Factor Profile According to the ICF Classification}

The ICF classification categories presented in Table 3 indicate risk factors which need to be monitored in secondary prevention of CVD. The chart represents percentage distribution of these risk factors according to the clinical type of prior stroke.

For the category "extremely high prevalence", risk factors such as heart rate and heart rhythm disorders, $>70 \%$ carotid stenosis, abnormal blood levels of $\mathrm{HbA} 1 \mathrm{c}>7 \%$, and NOAC/NSAID use were more frequently observed in patients with a history of IS. The percentage of patients with insomnia and liver impairment was significantly higher in the ICH group. The incidence of depression, increased blood pressure $>180 / 110 \mathrm{mmHg}$ and alcohol consumption was comparable between both groups. 


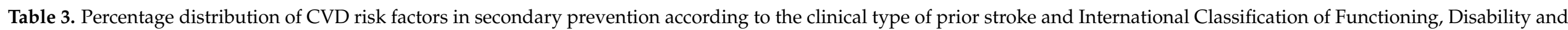
Health (ICF) classification categories.

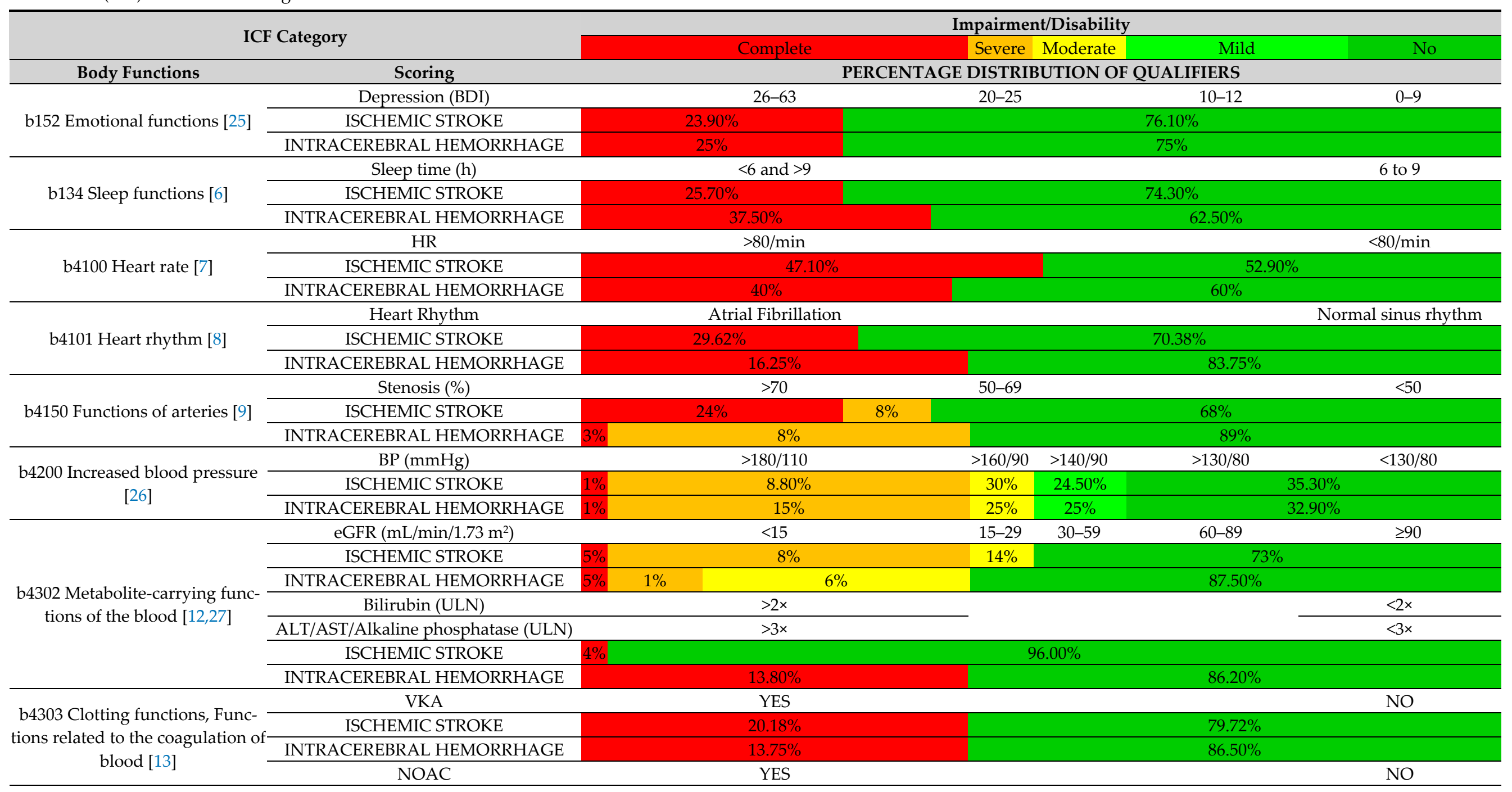


Table 3. Cont.

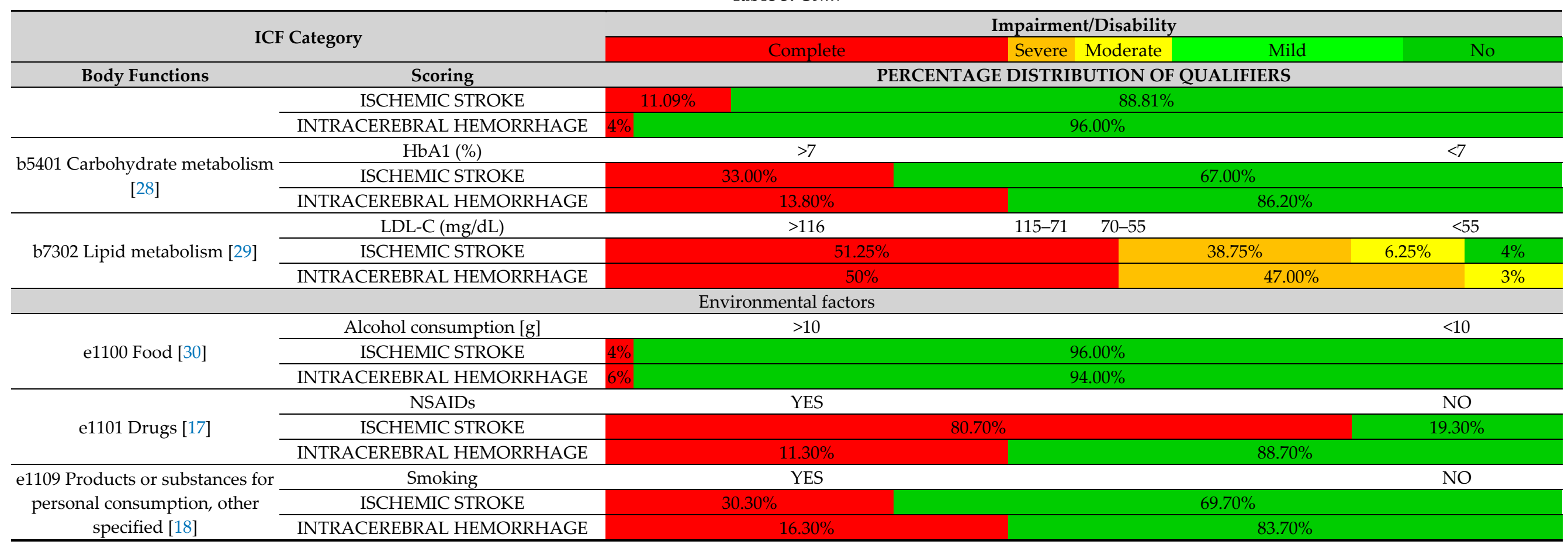

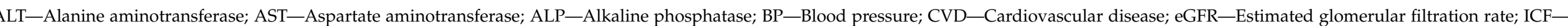

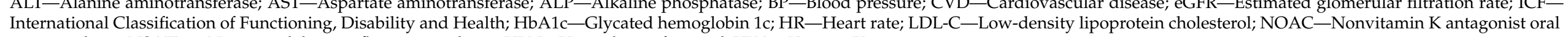
anticoagulants; NSAIDs-Nonsteroidal anti-inflammatory drugs; ULN-Upper limit of normal; VKA-Vitamin K antagonist. 
For the category "high prevalence", risk factor of glomerular filtration rate (eGFR) $15-29 \mathrm{~mL} / \mathrm{min} / 1.73 \mathrm{~m}^{2}$ was more frequently observed in patients with a history of IS. However, blood pressure $>160 / 90 \mathrm{mmHg}$ and LDL-C levels between 71 and $115 \mathrm{mg} \%$ were more common in patients with a history of ICH. The incidence of $50-69 \%$ carotid stenosis was comparable between IS and ICH groups.

For the category "moderate prevalence", risk factors such as blood pressure $>140 / 90 \mathrm{mmHg}$ and LDL-C levels between 70 and $55 \mathrm{mg} \%$ were more commonly observed in the IS group compared to ICH group.

\section{Discussion}

Stroke is the second most common cause of death globally and the leading cause of disability among adults in most countries in the world [31]. The increase in the incidence of stroke is strongly correlated with increased lifespan and increased proportion of the population aged 65+ [32]. The results of the research presented in this paper suggest that, for the study population, intracerebral hemorrhage was more commonly observed than ischemic stroke in younger individuals (Table 1). These findings are consistent with the results provided by Yamada et al. [33]. Like Zhang et al. [34], in this paper we demonstrated that the incidence of hypertension, coronary heart disease, chronic heart failure, carotid artery disease and type 2 diabetes mellitus was higher in patients with a history of ischemic stroke (Table 1). However, epilepsy was more commonly observed in patients with a history of intracerebral hemorrhage compared to those with a history of ischemic stroke (Table 1). A study by Feyiss et al. [35] has yielded similar results. They demonstrated that the reported incidence of seizure episodes related to previous stroke varied significantly from $2 \%$ for IS patients to $20 \%$ for ICH patients.

The presence of modifiable risk factors is associated both with the risk of recurrent CVD events and increased mortality and disability rates [36]. The risk factors and the stratification of CVD risk factors may change over time and should be kept up to date [37]. The incidence of risk factors for recurrent CVD events according to the clinical type of prior stroke in the study population is provided in Tables 2 and 3. The results showing differences in risk factors between patients with IS and ICH are related to the pathogenetic differences between these groups. These data suggest that atrial fibrillation/flutter and abnormal heart rate were more common in patients with a history of ischemic stroke. Lip et al. in their study [8] have shown that receiving a new-onset AF (atrial fibrillation) diagnosis after ischemic stroke was highly associated with recurrent stroke. Blood pressure $>140 / 90 \mathrm{mmHg}$ is another risk factor more commonly observed in patients with ischemic stroke. Our results are in line with findings by Liu et al. [10] who provided the evidence that blood pressure lowering in patients with a history of stroke reduces the incidence of recurrent CVD events. As we demonstrated in our research, carotid artery stenosis $>70 \%$ is also more common in patients with a prior history of ischemic stroke. Orrapin et al. [9] found that this risk factor is associated with increased risk of recurrent CVD events. Diabetic patients are more susceptible to atherosclerosis. Wu et al. [14] demonstrated that abnormal levels of glycated hemoglobin are independent predictors for the risk of recurrent ischemic stroke. These findings are consistent with data provided in Tables 2 and 3. Our results also suggest that the prevalence of smoking and NSAID/NOAC use is higher among patients with a history of ischemic stroke. Active smoking may lead to recurrent CVD events. Cessation of cigarette smoking after an ischemic stroke is associated with decreased 5-year risk of stroke, myocardial infarction or death [18]. According to Gerner et al. [13] and Narum et al. [17], the use of NOAC and NSAID is associated with increased risk of intracerebral hemorrhage.

In our study we demonstrated that sleeping disorders were more common in patients with a prior history of intracerebral hemorrhage than in those with a history of ischemic stroke, which is in line with findings by Cappuccio et al. [6] Abnormal results of certain liver function tests were also more commonly observed in this patient population. A study by Pisters et al. [12] revealed that bilirubin levels $>2 \times$ upper limit of normal combined with 
aspartate aminotransferase/alanine aminotransferase/alkaline phosphatase levels $>3 \times$ upper limit of normal are associated with an increased risk of intracerebral hemorrhage.

The vast majority of studies investigated the impact of a single risk factor [38] or several risk factors [39] on primary prevention of CVD. Risk factors related to the occurrence of qualifier level 4, which are marked in red, require absolute monitoring in the secondary prevention of stroke (Table 3). In patients with a history of ischemic stroke, particular attention should be paid to the occurrence of heart rate and rhythm disturbances, carotid artery stenosis $>70 \%$, abnormal $\mathrm{HbA} 1 \mathrm{c}$ levels $>7 \%$ and the use of NOAC/NSAIDs as factors determining the recurrence of a CVD events. On the other hand, after patients have suffered an intracerebral hemorrhage, particular attention should be paid to the occurrence of liver dysfunction and insomnia. The percentage distribution of risk factors for recurrent CVD events according to the ICF classification categories, presented in Table 3, provides information about all recognized risk factors and their prevalence based on the type of prior stroke, gathered in one place and at the same time aims to help healthcare professionals make the best decisions regarding the secondary prevention of cardiovascular disease. Moreover, it enables the users to readily assess individual risk factor categories and create "dynamic charts" to guide clinical decision making.

\section{Conclusions}

(1) The incidence and type of risk factors for recurrent CVD events vary according to the clinical type of prior stroke.

(2) The ICF classification system can be used to evaluate risk factors for recurrent CVD events based on the clinical type of prior stroke.

(3) The use of a single tool that describes multiple risk factors for recurrent CVD events, such as ICF assessment sheet, may increase the effectiveness of secondary prevention interventions, and thus decrease the risk of subsequent cardiovascular events.

\section{Limitations}

The limitations of our study were the lack of analysis of risk factors in relation to personal factors such as age and gender, as these factors are not organized into categories and qualifiers in the current version of the ICF classification. Another issue is the failure to consider BMI as a well-known risk factor for a recurrent CVD events due to the lack of data enabling its calculation based on the available medical documentation. Furthermore, some categories of ICF classification could only be represented as extreme qualifiers (4 or 0 ) without the possibility of using intermediate values.

Author Contributions: Conceptualization, M.L., E.C. and P.L.; investigation, M.L., E.C. and A.W.; methodology, M.L., E.C., A.W. and P.L.; writing-original draft, M.L.; writing-review and editing, M.L. and P.L. All authors have read and agreed to the published version of the manuscript.

Funding: The authors received no financial support for the research, authorship, and/or publication of this article.

Institutional Review Board Statement: The study was conducted according to the guidelines of the Declaration of Helsinki and approved by the Ethics Committee of the Karol Marcinkowski Memorial Medical University in Poznań (protocol code 810/2017, 22 June 2017).

Informed Consent Statement: Patient consent was waived due to a high number of patients retrospectively involved in the study, an approval from the Ethics Committee of the Karol Marcinkowski Memorial Medical University in Poznań was obtained to perform data analysis without the individual informed consent of each patient.

Data Availability Statement: The data presented in this study are available on request from the corresponding author. The data are not publicly available due to ethical restrictions.

Conflicts of Interest: The authors declare no potential conflict of interest with respect to the research, authorship, and/or publication of this article. 


\section{References}

1. Roth, G.A.; Forouzanfar, M.H.; Moran, A.E.; Barber, R.; Nguyen, G.; Feigin, V.L.; Naghavi, M.; Mensah, G.A.; Murray, C.J. Demographic and epidemiologic drivers of global cardiovascular mortality. N. Engl. J. Med. 2015, 372, 1333-1341. [CrossRef]

2. Nowacki, P.; Bajer-Czajkowska, A.; Masztalewicz, M. Clinical characteristics of early and late recurrent ischaemic stroke. Neurol. Neurochir. Pol. 2010, 44, 123-130. [CrossRef]

3. Mendis, S.; Abegunde, D.; Yusuf, S.; Ebrahim, S.; Shaper, G.; Ghannem, H.; Shengelia, B. WHO study on Prevention of REcurrences of Myocardial Infarction and StrokE (WHO-PREMISE). Bull. World Health Organ. 2005, 83, 820-829.

4. Fitzsimons, D.; Stepińska, J.; Kerins, M.; Piepoli, M.F.; Hill, L.; Carson, M.A.; Prescott, E. Secondary prevention and cardiovascular care across Europe: A survey of European Society of Cardiology members' views. Eur. J. Cardiovasc. Nurs. 2020, 19, $201-211$. [CrossRef]

5. Yuan, H.W.; Wang, C.X.; Zhang, N.; Bai, Y.; Shi, Y.Z.; Zhou, Y.; Wang, Y.L.; Zhang, T.; Zhou, J.; Yu, X.; et al. Poststroke depression and risk of recurrent stroke at 1 year in a Chinese cohort study. PLoS ONE 2012, 7, e46906. [CrossRef]

6. Cappuccio, F.P.; Cooper, D.; D’Elia, L.; Strazzullo, P.; Miller, M.A. Sleep duration predicts cardiovascular outcomes: A systematic review and meta-analysis of prospective studies. Eur. Heart J. 2011, 32, 1484-1492. [CrossRef]

7. Woodward, M.; Webster, R.; Murakami, Y.; Barzi, F.; Lam, T.H.; Fang, X.; Suh, I.; Batty, G.D.; Huxley, R.; Rodgers, A.; et al. The association between resting heart rate, cardiovascular disease and mortality: Evidence from 112,680 men and women in 12 cohorts. Eur. J. Prev. Cardiol. 2014, 21, 719-726. [CrossRef]

8. Lip, G.Y.; Hunter, T.D.; Quiroz, M.E.; Ziegler, P.D.; Turakhia, M.P. Atrial fibrillation diagnosis timing, ambulatory ECG monitoring utilization and risk of recurrent stroke. Circ. Cardiovasc. Qual. Outcomes 2017, 10, e002864. [CrossRef]

9. Orrapin, S.; Rerkasem, K. Carotid endarterectomy for symptomatic carotid stenosis. Cochrane Database Syst. Rev. 2017, 6, CD001081. [CrossRef] [PubMed]

10. Liu, L.; Wang, Z.; Gong, L.; Zhang, Y.; Thijs, L.; Staessen, J.A.; Wang, J. Blood pressure reduction for the secondary prevention of stroke: A Chinese trial and a systematic review of the literature. Hypertens. Res. 2009, 32, 1032-1040. [CrossRef] [PubMed]

11. Weiner, D.E.; Tighiouart, H.; Stark, P.C.; Amin, M.G.; MacLeod, B.; Griffith, J.L.; Salem, D.N.; Levey, A.S.; Sarnak, M.J. Kidney disease as a risk factor for recurrent cardiovascular disease and mortality. Am. J. Kidney Dis. 2004, 44, 198-206. [CrossRef]

12. Pisters, R.; Lane, D.A.; Nieuwlaat, R.; de Vos, C.B.; Crijns, H.J.; Lip, G.Y. A novel userfriendly score (HAS-BLED) to assess 1-year risk of major bleeding in patients with atrial fibrillation: The Euro Heart Survey. Chest 2010, 138, 1093-1100. [CrossRef]

13. Gerner, S.T.; Kuramatsu, J.B.; Sembill, J.A.; Sprügel, M.I.; Hagen, M.; Knappe, R.U.; Endres, M.; Haeusler, K.G.; Sobesky, J.; Schurig, J.; et al. Characteristics in non-vitamin K antagonist oral anticoagulant-related intracerebral hemorrhage. Stroke 2019, 50, 1392-1402. [CrossRef] [PubMed]

14. Wu, S.; Shi, Y.; Wang, C.; Jia, Q.; Zhang, N.; Zhao, X.; Liu, G.; Wang, Y.; Liu, L.; Wang, Y.; et al. Glycated hemoglobin independently predicts stroke recurrence within one year after acute first-ever non-cardioembolic strokes onset in A Chinese cohort study. PLoS ONE 2013, 8, e80690. [CrossRef] [PubMed]

15. Stroke Prevention by Aggressive Reduction in Cholesterol Levels (SPARCL) Investigators. High-dose atorvastatin after stroke or transient ischemic attack. N. Engl. J. Med. 2006, 355, 549-559. [CrossRef]

16. Ois, A.; Gomis, M.; Rodríguez-Campello, A.; Cuadrado-Godia, E.; Jiménez-Conde, J.; Pont-Sunyer, C.; Cuccurella, G.; Roquer, J. Factors associated with a high risk of recurrence in patients with transient ischemic attack or minor stroke. Stroke 2008, 39, 1717-1721. [CrossRef]

17. Narum, S.; Solhaug, V.; Myhr, K.; Brørs, O.; Kringen, M.K. Characterisation of non-warfarin-associated bleeding events reported to the Norwegian spontaneous reporting system. Eur. J. Clin. Pharmacol. 2013, 69, 1445-1452. [CrossRef]

18. Epstein, K.A.; Viscoli, C.M.; Spence, J.D.; Young, L.H.; Inzucchi, S.E.; Gorman, M.; Gerstenhaber, B.; Guarino, P.D.; Dixit, A.; Furie, K.L.; et al. Smoking cessation and outcome after ischemic stroke or TIA. Neurology 2017, 89, 1723-1729. [CrossRef]

19. Słowik, A.; Wnuk, M.; Brzegowy, P.; Chrzanowska-Waśko, J.; Golenia, A.; Łasocha, B.; Włoch-Kopeć, D.; Ferens, A.; Serednicki, W.; Jarocki, P.; et al. Mechanical thrombectomy in acute stroke-Five years of experience in Poland. Neurol. Neurochir. Pol. 2017, 51, 339-346. [CrossRef] [PubMed]

20. Strazzullo, P.; D’Elia, L.; Cairella, G.; Garbagnati, F.; Cappuccio, F.P.; Scalfi, L. Excess body weight and incidence of stroke: Meta-analysis of prospective studies with 2 million participants. Stroke 2010, 41, e418-e426. [CrossRef]

21. Adams, R.J.; Chimowitz, M.I.; Alpert, J.S.; Awad, I.A.; Cerqueria, M.D.; Fayad, P.; Taubert, K.A.; Stroke Council and the Council on Clinical Cardiology of the American Heart Association; American Stroke Association. Coronary risk evaluation in patients with transient ischemic attack and ischemic stroke: A scientific statement for healthcare professionals from the Stroke Council and the Council on Clinical Cardiology of the American Heart Association/American Stroke Association. Stroke 2003, 34, $2310-2322$. [PubMed]

22. Kohler, F.; Selb, M.; Escorpizo, R.; Kostanjsek, N.; Stucki, G.; Riberto, M.; International Society of Physical and Rehabilitation Medicine Sub-Committee Implementation of the ICF; Participants of the São Paulo ISPRM-World Health Organization Workshop. Towards the joint use of ICD and ICF: A call for contribution. J. Rehabil. Med. 2012, 10, 805-810. [CrossRef]

23. Chen, S.; Tao, J.; Tao, Q.; Fang, Y.; Zhou, X.; Chen, H.; Chen, Z.; Huang, J.; Chen, L.; Chan, C.C. Rater experience influences reliability and validity of the Brief International Classification of Functioning, Disability, and Health Core Set for Stroke. J. Rehabil. Med. 2016, 48, 265-272. [CrossRef] 
24. Lee, H.; Seo, S.; Song, J. Information on functioning found in the medical records of patients with stroke. J. Phys. Ther. Sci. 2016, 28, 2722-2726. [CrossRef]

25. Ceccarini, M.; Manzoni, G.M.; Castelnuovo, G. Assessing depression in cardiac patients: What measures should be considered? Depress. Res. Treat. 2014, 2014, 148256. [CrossRef]

26. Cuspidi, C.; Tadic, M.; Grassi, G.; Mancia, G. Treatment of hypertension: The ESH/ESC guidelines recommendations. Pharmacol. Res. 2018, 128, 315-321. [CrossRef] [PubMed]

27. Inker, L.A.; Astor, B.C.; Fox, C.H.; Isakova, T.; Lash, J.P.; Peralta, C.A.; Kurella Tamura, M.; Feldman, H.I. KDOQI US commentary on the 2012 KDIGO clinical practice guideline for the evaluation and management of CKD. Am. J. Kidney Dis. 2014, 63, 713-735. [CrossRef]

28. Inzucchi, S.E.; Bergenstal, R.M.; Buse, J.B.; Diamant, M.; Ferrannini, E.; Nauck, M.; Peters, A.L.; Tsapas, A.; Wender, R.; Matthews, D.R. Management of hyperglycemia in type 2 diabetes, 2015: A patient-centered approach: Update to a position statement of the American Diabetes Association and the European Association for the Study of Diabetes. Diabetes Care 2015, 38, 140-149. [CrossRef]

29. Schwartz, G.G.; Steg, P.G.; Szarek, M.; Bhatt, D.L.; Bittner, V.A.; Diaz, R.; Edelberg, J.M.; Goodman, S.G.; Hanotin, C.; Harrington, R.A.; et al. Alirocumab and cardiovascular outcomes after acute coronary syndrome. N. Engl. J. Med. 2018, 379, 2097-2017. [CrossRef]

30. Wood, A.M.; Kaptoge, S.; Butterworth, A.S.; Willeit, P.; Warnakula, S.; Bolton, T.; Paige, E.; Paul, D.S.; Sweeting, M.; Burgess, S.; et al. Risk thresholds for alcohol consumption: Combined analysis of individual-participant data for 599912 current drinkers in 83 prospective. Lancet 2018, 391, 1513-1523. [CrossRef]

31. Mozaffarian, D.; Benjamin, E.J.; Go, A.S.; Arnett, D.K.; Blaha, M.J.; Cushman, M.; Das, S.R.; De Ferranti, S.; Després, J.P.; Fullerton, H.J.; et al. Heart Disease and Stroke Statistics-2016 Update: A Report from the American Heart Association. Circulation 2016, 133, e38-e360. [CrossRef] [PubMed]

32. Truelsen, T.; Piechowski-Jóźwiak, B.; Bonita, R.; Mathers, C.; Bogousslavsky, J.; Boysen, G. Stroke incidente and prevalence in Europe: A review of available data. Eur. J. Neurol. 2006, 13, 581-598. [CrossRef]

33. Yamada, Y.; Metoki, N.; Yoshida, H.; Satoh, K.; Ichihara, S.; Kato, K.; Kameyama, T.; Yokoi, K.; Matsuo, H.; Segawa, T.; et al. Genetic risk for ischemic and hemorrhagic stroke. Arterioscler. Thromb. Vasc. Biol. 2006, 26, 1920-1925. [CrossRef]

34. Zhang, J.; Wang, Y.; Wang, G.N.; Sun, H.; Sun, T.; Shi, J.Q.; Xiao, H.; Zhang, J.S. Clinical factors in patients with ischemic versus hemorrhagic stroke in East China. World J. Emerg. Med. 2011, 2, 18-23. [CrossRef] [PubMed]

35. Feyissa, A.M.; Hasan, T.F.; Meschia, J.F. Stroke-related epilepsy. Eur. J. Neurol. 2019, 26, 1-18. [CrossRef]

36. Vickrey, B.G.; Rector, T.S.; Wickstrom, S.L.; Guzy, P.M.; Sloss, E.M.; Gorelick, P.B.; Garber, S.; McCaffrey, D.F.; Dake, M.D.; Levin, R.A. Occurrence of secondary ischemic events among persons with atherosclerotic vascular disease. Stroke 2002, 33, 901-906. [CrossRef]

37. Kotlega, D.; Gołąb-Janowska, M.; Meller, A.; Pawlukowska, W.; Nowacki, P. Detection of stroke risk factors over the decade in the Polish population of patients with ischemic stroke. Adv. Psychiatry Neurol. 2019, 28, 83-87. [CrossRef]

38. Yannoutsos, A.; Dreyfuss Tubiana, C.; Safar, M.E.; Blacher, J. Optimal blood pressure target in stroke prevention. Curr. Opin. Neurol. 2017, 30, 8-14. [CrossRef]

39. Savoia, C.; Sada, L.; Volpe, M. Blood pressure control versus atrial fibrillation management in stroke prevention. Curr. Hypertens. Rep. 2015, 17, 553. [CrossRef] 